EVISTA ANDALUZA DE ANTROPOLOGÍA.

NÚMERO 5: APORTACIONES Y POTENCIALIDADES DE LA ANTROPOLOGÍA DE LA SALUD.

SEPTIEMBRE DE 2013

ISSN 2174-6796

[pp. 151-177]

http://dx.doi.org/10.12795/RAA.2013.i05.08

Fecha de Recepción: 19-04-2013

Fecha de Aceptación: 21-07-2013

\title{
AMBIVALENCIA Y ORDEN COLONIAL ESPANOL EN EL SAHARA OCCIDENTAL: (1969-1973)
}

Juan Carlos Gimeno Martín

Juan Ignacio Robles Picón

Universidad Autónoma de Madrid

\section{Resumen.}

En este artículo exploramos las dinámicas de las relaciones coloniales establecidas entre la sociedad saharaui y la sociedad metropolitana. La penetración colonial española en el territorio del Sahara Occidental desde 1884 fue parcial, lenta e incompleta. Sólo desde 1958, en lo que puede considerarse una "segunda colonización", se dieron cambios sustantivos en las relaciones coloniales con el objetivo de desarrollar el Sahara Español como una provincia española y asegurar el control efectivo de sus fronteras con los territorios vecinos, que se conformaron como países independientes: Marruecos, Mauritania y Argelia. La naturaleza paternalista de la colonización española y la participación de la sociedad saharaui a partir de sus estructuras de organización tribales produjeron un tipo específico de relaciones coloniales, diferentes a la que se dieron en los territorios vecinos. Dichas relaciones han sido consideradas, tanto por saharauis como por los españoles, relaciones familiares, y débiles. Esta imagen, de mutua consideración, se ha reforzado, dado el apoyo de la sociedad civil española a la causa saharaui. Sin embargo, hubo momentos en la historia del Sahara Occidental donde estas relaciones coloniales adquirieron tintes dramáticos (particularmente alrededor de los años 1930-1934/1956-1958). Desde 1969 
con el surgimiento de la organización liderada por Mohamed uld El Hadj Brahim uld Lebsir, conocido por Basiri, la represión violenta de Zemla, el 17 de junio de 1970, que conllevó la desaparición del líder saharaui, y el posterior surgimiento del Polisario en 1973, que promovió la lucha por la independencia del Sahara Occidental ${ }^{1}$, con el apoyo mayoritario de la población saharaui, la relaciones coloniales revelaron sus verdaderos límites. Este artículo explora a partir de las historias vividas por personas saharauis en una serie de situaciones extremas en 1970, 1974 y 1975 la naturaleza profunda de la ambivalencia colonial en el Sahara Occidental.

\title{
Palabras clave.
}

Ambivalencia colonial, Resistencia, Sahara Occidental 1969-1976, Investigación colaborativa, Recuperación de la memoria histórica, Poscolonialidad

\begin{abstract}
.
In this article we explore the dynamics of colonial relations in Western Sahara. The Spanish colonial penetration in Western Sahara since 1884 was partial, slow and incomplete . Only since 1958, which could be considered the beginning of a "second colonization", substantive changes were colonial relations with the aim of developing the Spanish Sahara as a Spanish province and ensuring effective control of its borders with neighboring territories, which were formed as independent countries: Morocco, Mauritania and Algeria. The paternalistic nature of Spanish colonization and the Saharawi society participation from tribal organizational structures produced a specific type of colonial relations, different to that given in the neighboring territories. Such relationships have been considered by both parties as family and weak. However, there were moments in the history of Western Sahara where these colonial relationships acquired most dramatic dyes (particularly around the years 1930-1934/1956-1958). Since 1969 emerges the organization led by Mohamed Ould El Hadj Brahim Ould Lebsir, known for Basiri. Zemla violent repression of the June 17, 1970, which led to the disappearance of the Sahrawi leader, resulted the emergence of Polisario, 1973, which promoted the fight for the independence of Western Sahara. With the majority support of the Sahrawi population, the colonial relationships revealed their true limits. Starting from the life stories of Saharawi people lived by a series of extremes in 1970, 1974 and 1975, this
\end{abstract}

\footnotetext{
1. El gobierno español promovió el PUNS (Partido de Unión Nacional Saharuis), en un intento de dividir a la población saharaui introduciendo una organización afin a sus intereses. Este proyecto constituyó un fracaso, porque fue una iniciativa tardía, por la oposición general de la población saharaui movilizada en torno al Frente Polisario, y por la deserción del principal dirigente del partido, JaliHenna Rachid, que huyó a Marruecos.
} 
article explores the profound nature of colonial ambivalence in Western Sahara.

Keywords. Colonial ambivalence, Colonial resistance, Western Sahara, 1969-1975, Collaborative investigation, postcoloniality

\section{1.}

En este artículo exploramos la ambivalencia ${ }^{2}$ de las relaciones coloniales entre la sociedad saharaui y la sociedad de la metrópoli en el Sahara Occidental. La penetración colonial española en el territorio del Sahara Occidental desde 1884 fue parcial, lenta e incompleta. Sólo desde 1958 se dieron cambios sustantivos en las relaciones coloniales con el proyecto de desarrollar el Sahara Español como una provincia española y con el control efectivo de sus fronteras con los territorios vecinos, Marruecos, Mauritania y Argelia; países que surgieron como resultado de los procesos de descolonización que dieron lugar a estos tres países.

\subsection{Una anotación metodológica}

Este artículo es un primer resultado de la co-laboración entre investigadores saharauis y europeos que han compartido, desde 2003, dos proyectos: un proyecto de recuperación

2. Homi Bhabha utiliza los términos de ambivalencia (del discurso colonial) y mimetismo para caracterizar las relaciones coloniales (en el contexto de la colonización británica de la India). Bhabha sostiene que el discurso colonial es ambivalente, porque -como había sugerido Fanon- el "otro", el nativo, es a la vez objeto de desprecio y deseo. La ambivalencia describiría en este caso un proceso simultáneo de negación y de identificación con el otro. Sólo a través del otro, construye el sujeto su identidad y sitúa su deseo de la diferencia. Es la percepción de la similitud, de la familiaridad, de lo compartido, lo que produce el temor y el rechazo. Es la amenaza de la analogía, el son como nosotros, pero no son "nosotros". "Son como nosotros, pero no del todo". A juicio de Bhabha, sería evidente que el mimetismo está asociado al temor a una pérdida y que, como toda repetición que no es idéntica al original, desplaza la identidad y la definición de ese original. ("El mimetismo y el hombre. La ambivalencia del discurso colonial" en El lugar de la cultura, Buenos Aires, Manantial, 2002).

Es interesante para nuestro objetivo en este artículo destacar que en la aproximación de Homi Bhabha, no hay una división neta entre colonizador y colonizado, sino una frontera difusa, una relación compleja, mimética y ambivalente, una final hibridación que es, al cabo, una forma de resistencia. La relación colonial entraña la disolución del discurso occidental mediante su continua e inevitable interpretación en un medio social, religioso y cultural diverso. No sólo, pues, el colonizador construye discursivamente al colonizado, sino que también el colonizado construye al colonizador, o éste se construye a sí mismo asumiendo la imagen de sí que procura la adopción del punto de vista del colonizado. La búsqueda de momentos de resistencia entonces, ha de perseguirse en los espacios de contacto, en la impureza de la hibridación, en la imitación... 
de la memoria oral de la historia saharaui de los ancianos y ancianas saharauis (proyecto: "Cuéntame abuelo/a"), impulsado por el Ministerio de Cultura saharaui, y una investigación, realizada en el contexto de los proyecto $\mathrm{I}+\mathrm{D}+\mathrm{i}$, cuyo objetivo es la recuperación de la(s) memoria(s) (saharaui y española) de la colonización del Sahara . Co-laborar es "trabajar" junto a otros. Esta tarea conlleva cuestiones éticas y prácticas (Leyva, Burguete y Speed, 2003). Obliga a cambios radicales en las prácticas académicas y de sus contrapartes. Exige también nuevas formas de escritura. Una manera común de manifestar la producción colaborativa del conocimiento histórico y etnográfico es la de citar regular y extensamente los testimonios de los informantes, en lugar de parafrasearlos. Con frecuencia esto sólo ha sido una falsa solución; las citas son siempre puestas en escena por los autores que los citan como testimonios confirmativos de su plan de argumentación. Mirando más allá de la cita, se puede imaginar una polifonía más radical conformada con los textos compuestos por la suma de aportaciones de los historiadores/etnógrafos y también por aquellos sobre los que trata la historia, con sus distintas voces. De nuevo, con frecuencia, esta estrategia narrativa sólo desplaza la autoridad narrativa, confirmando la orquestación final de un solo autor de todos los discursos del texto.

Abogamos aquí, por otro tipo de trabajo de investigación y por otro tipo de escritura, en el que se incluya la co-escritura (escribir con) y la escritura en presencia de los otros sobre/desde los que escribimos, que es la que ahora intentamos practicar en este artículo. El desafío, es acordar con nuestros co-laboradores un espacio textual autónomo; donde transcribir sus testimonios, sus palabras con la longitud suficiente, para que hablen por sí mismas, y se resistan a las tácticas textuales de aquellos que los utilizamos desde fuera, haciéndoles decir, citando sus propias palabras, aquello que no dicen. En esas ocasiones conseguimos trasladar en nuestros textos distorsiones y hasta mentiras cuando pretendemos decir la verdad (con frecuencia legitimada con los términos de objetividad y neutralidad).

Nuestro compromiso es aquí, recoger, tanto como podamos, las voces de los saharauis y tomar sus palabras en sus propios términos. Es por ello que presentamos largas citas, inusuales en los trabajos académicos. Con ellas buscamos mantener un diálogo con los autores y personajes que se convocan aquí, tratando de recoger no sólo lo que dicen, sino también la manera en que lo dicen. En este sentido cobran relevancia no solamente los contenidos de lo dicho, sino también los lenguajes usados, lo que nos permite transmitir y difundir este conocimiento co-producido.

\section{2.}

La naturaleza paternalista de la colonización española y la participación de la sociedad saharaui a partir de sus estructuras de organización como sociedad segmentada produjeron relaciones coloniales, a diferencia de los territorios vecinos, consideradas 
por ambas partes como familiares y débiles. Estas relaciones contrastan con las que se mantuvieron en la colonización francesa. Hay que entender que para la sociedad sahariana, la colonización, que significaba la penetración de las sociedades europeas, era una sola, si bien operaba con distintos grados de fuerza. Las confrontaciones con las fuerzas francesas fueron una constante desde finales del siglo XIX y hasta la pacificación de 1934. El énfasis en las historias coloniales diferenciadas de los distintos países europeos dificulta la comprensión de la concepción vernácula de la colonización por parte de la sociedad sahariana, así como la comprensión de sus estrategias para enfrentarla. La distinta naturaleza de la colonización española y francesa en la región es un dato para la comprensión cabal de las formas en que la sociedad sahariana enfrentó el proceso colonizador, el establecimiento de las fronteras sobre un mapa, y su consolidación en el primer tercio del siglo XX.

La colonización española es percibida y construida como un proceso relativamente suave que afectó relativamente el orden societal tradicional saharaui hasta bien entrados los años 1960. Esta percepción actual se corresponde con una construcción del hecho colonial por parte de los saharauis que busca no acentuar sus diferencias con un país que puede ser importante en la gestión de la descolonización, como potencia administradora de iure del territorio, si bien no ejerce esa función, y por la gran sintonía que existe entre la causa saharaui y la sociedad civil española. El carácter suave y amistoso de la colonización española corresponde también con una construcción por parte de militares y políticos españoles sobre un orden colonial amable y paternalista (Correale, 2013), que fue poco intrusivo. Esta misma construcción de la cara amable de la colonización, impide a algunos militares y analistas políticos entender la emergencia del Polisario, como legítimo movimiento de liberación nacional y su contestación armada a la colonización. Algo para cuya comprensión nos viene bien considerar desde las aportaciones de intelectuales como el antropólogo Trouillot (1995) en la consideración de las dificultades del imperio francés para entender la revolución haitiana, las de Guha (1982) para denunciar la incapacidad de las historiografías modernas al considerar la respuesta no moderna al colonialismo y las de Frank Fanon reclamando la condición de sujetos históricos de las poblaciones subalternas. Estos tres autores hablan desde los silenciamientos de la historia de los procesos de lucha y construcción histórica de las poblaciones que denominamos subalternas.

La reconsideración de las relaciones coloniales en el Sahara Occidental, debe enfrentar, para una mejor comprensión histórica, el hecho de que más allá de las imágenes amables que se representan hegemónicamente, hubo momentos de su historia donde estas relaciones coloniales adquirieron tintes más dramáticos, incluso trágicos, como los periodos en los que España, convergiendo con la lógica del control colonial francés, reforzó las fronteras (particularmente alrededor de los años 1910-1913, 1930-1934, y 1956-1958) e impidió expresiones alternativas para la constitución de un proyecto 
social y político adverso al control colonial (1958 y 1970/1973). En 1958, al calor de las luchas por las independencias nacionalistas en el norte de África, y desde 1970 con el surgimiento de una organización que reclamaba la autonomía del Sahara Occidental, liderada por Basiri. La represión violenta de las aspiraciones de este movimiento, que se produjo el 17 de junio en el barrio de Zemla, en El Aiún, con la consiguiente desaparición forzada del mismo Basiri, llevó al surgimiento del Frente Polisario, movimiento armado apoyado mayoritariamente por la población saharaui. Fue en estos momentos en los que la situación colonial reveló sus limitaciones. Y los que nos permiten intentar realizar una historia alternativa del Sahara Occidental, una contrahistoria, en los términos que utilizó Foucault en Genealogía del Racismo (Gimeno y Robles, 2013).

Algunos protagonistas de las acciones colonizadoras, en particular, parte del estamento militar español, ha responsabilizado a la insurgencia saharaui de la situación que llevó a la salida prematura de España del territorio, en 1975/1976, sin poder organizar una transición descolonizadora como la que se preparaba, siguiendo los pasos previstos por Naciones Unidas. Estos argumentos se basan en la consideración de un orden colonial basado en unas relaciones de dominación que enfatizaban el bienestar cotidiano y las relaciones de buena convivencia de la población saharaui y los funcionarios españoles, así como el carácter paternal del régimen de Franco con la población saharaui. De hecho, muchos saharauis presentan relatos del tiempo de la colonia donde enfatizan las buenas relaciones entre el Sahara y la metrópoli, y los más ancianos se declaran públicamente "franquistas" (Correale, 2013) y consideran que el dictador nunca hubiera entregado el Sahara Occidental a los países vecinos (Dalmases, 2013).

Nosotros creemos que en este caso es preciso ver las relaciones coloniales en el Sahara Occidental como relaciones producidas por la tensión estructural entre la metrópoli, y sus estrategias propias de dominación del territorio (para sus propios fines), y la sociedad subalterna, y sus propias estrategias de acomodación y resistencia. Esta tensión puede detectarse en muchos ámbitos de las relaciones coloniales en el Sahara Occidental, y se basa en una distinción irreductible del colonialismo, establecida entre metrópoli y colonia, una distinción que no puede ser ignorada. Dicha distinción parte de la voluntad de la metrópoli, como sujeto no sólo que es moderno, sino que puede, y debe, "dar" la modernidad a los otros (no modernos/ coloniales), introduciéndoles así en la "historia", reduciéndoles a la condición de objetos.

También en la colonización española del Sahara Occidental, la sociedad saharaui se construyó en el imaginario colonial y en sus prácticas como una sociedad tradicional y no moderna. Es esa brecha, entre la naturaleza moderna de uno de los sujetos (la metrópoli, en este caso España) y la naturaleza no moderna o tradicional del otro (la sociedad saharaui), que hace de la convivencia entre españoles y saharauis un proyecto imposible, dado que, a pesar de la convivencia, como diría Johanes Fabian (2002), no participan del mismo tiempo. Coexistían, es cierto, y se encontraban, pero no lo hacían como 
contemporáneos. Los saharauis, para el régimen colonial, vivían en un tiempo presente, pero seguían una lógica del pasado (tradicional). Ser contemporáneos, ser reconocidos como sujetos en la construcción del mundo contemporáneo, es una condición para poder participar en la construcción común del mundo en el que habitamos. El colonialismo niega esa condición a las sociedades colonizadas. Esta brecha fue puesta de manifiesto por Fanon, en Los condenados de la Tierra, por Amílcar Cabral, y por tantos otros líderes de la descolonización africana de la segunda mitad del siglo XX. Para ellos, había una violencia en la colonización que sería respondida por una contraviolencia, comenzando una dialéctica de lucha que sólo debería terminar, no con la victoria de los colonizados sobre los colonizadores para invertir un orden, sino en un nuevo orden, donde las sociedades colonizadoras y colonizadas trascendieran ambas la lógica de la colonización. Por ello Fanon insistía en la necesidad de descolonizar a los colonizadores.

\section{3.}

Es cierto que ha habido en la historia muchas modalidades de colonialismo. Y la que se produjo en el Sahara en el encuentro entre la metrópoli española y la sociedad sahariana, tiene sus particularidades. Creemos útil utilizar la distinción entre dominación y hegemonía para tratar de entender la naturaleza de la colonización española del Sahara Occidental. Esta distinción, que proviene de Gramsci en sus Cuadernos de la Cárcel, ha sido reconsiderada y utilizada con gran acierto por R. Guha para entender la colonización británica de la India, donde se dio dominio, pero no hegemonía por parte de Gran Bretaña ${ }^{3}$. Lo mismo podemos decir del Sahara Español. La ausencia de hegemonía proporciona una situación histórica donde la subalternidad de las poblaciones colonizadas se da en un contexto de un amplio margen para el mantenimiento de referencias propias en la reproducción y transformación de la sociedad bajo el dominio colonial. Durante la colonización española, sólo a partir de 1958 se acentúa decididamente la presión de la metrópoli sobre las formas de vida de las poblaciones saharauis, con estrategias muy

3. Para Guha, en su concepción del poder, que utiliza en su trabajo sobre el colonialismo británico en la India, el poder se da siempre en una historia de dominación y subordinación. La hegemonía se refiere a una condición de la dominación (en su relación con la subordinación), de manera que en su composición orgánica, la persuasión sobrepasa la coerción. Definida en esos términos la hegemonía funciona como un concepto dinámico y mantiene incluso la estructura persuasiva del dominio, siempre y necesariamente abierta a la resistencia (cuyo otro polo, que también se da, es la colaboración). Al mismo tiempo evita, la yuxtaposición gramsciana de dominancia y hegemonía como antinomias. Para Guha esto último ha proporcionado un pretexto teórico para la fabricación de un absurdo liberal -la incoherente idea de un estado no coercitivo-, a pesar de que el propio trabajo de Gramsci iba en sentido contrario. Para Guha no puede haber sistema hegemónico donde la persuasión sobrepase a la coacción. Si así fuera no habría ninguna dominación, como tampoco ninguna hegemonía (Guha, 1997). 
activas que buscaron producir un cambio social: la provincialización del Sahara, no solo fue una estrategia para resistirse a la descolonización del territorio, tuvo efectos sobre las relaciones entre metrópoli y colonia, generando nuevas subjetividades y también nuevos ordenes sociales. La movilización social para la resistencia fue una de estas consecuencias, la creación de nuevas formas de ser saharaui, fue otra.

Bahia Mahmd Awah (2013) por un lado y Juan Carlos Gimeno y Mohamed Ali (2007) por otro, han empezado a incursionar en lo que puede ser un apasionante campo de investigación: el efecto de las transformaciones de las relaciones entre el desierto y la ciudad en el Sahara Occidental, así como las formas en que estos fueron percibidos y construidos por los propios saharauis. El terreno de los debates poéticos es especialmente fértil en este sentido, entre los poetas que defendían la vida en el medio rural frente a los que empezaban a ver la potencialidad de las ciudades como lugares del bien vivir (Awah, 2012). Por ejemplo, el debate entre Salama uld Eydud y su primo, Yedehlu uld Esid. El primero reclamaba la belleza y armonía de la vida en el desierto, que el segundo había dejado para vivir en la ciudad explorando nuevos horizontes para ganarse la vida.

Díganle a Yedehlu que esta morada que limpia el alma es todo agua, desde Tishia hasta El Mahyub,

El Guetma al pozo Deyan, también agua en Bashabshub

y en los montes de Ergab Ishirgan.

Llovió desde allí a la ladera sur de Leglat, al norte de Derraman.

Y que en este lugar en sí, su gente desborda alegría,

gozo a plena luna y trashumancia.

Díganle que aun en el Sahara hay jinetes

$y$ hombres de letras,

y yo lo que le puedo aconsejar de entre otras exhortaciones

que venga por aquí,

que ya debe hacer su paseo en estos lugares de patria4.

Así se daban debates, tornas poéticas, entre los que defendían un orden social que se desarrollaba en el desierto, en un equilibrio, si bien duro y difícil, entre los hombres y la naturaleza bajo la mirada de Alá, y los que reconocían y se plegaban a las nuevas leyes de un nuevo tiempo marcado por el ritmo de la vida moderna; los que creían tener el tiempo, y los que empezaban a medir el tiempo por el paso de la manillas en

4. Traducción del intelectual y poeta saharaui Bahia Mahmud Awah. 
un reloj (Gimeno y Ali, 2007). Entre 1958 y 1975 los motivos para la composición de la producción poética en el Sahara siguió siendo netamente oral, y no escrita (una característica de la modernidad), pero sus motivos se desbordaron para abordar debates como los anteriores, y también para incluir la crítica de la vida moderna y su conexión con el trasfondo del colonialismo: la producción de una vida moderna basada en el consumo, que constituye el trasfondo del poema de Alal Daf, compuesto en 1972. Alal tenía entonces 45 años. Nacido en el desierto, vivió en él hasta 1958. Aquel año, la política de "las tierras quemadas" llevada a cabo por el colonialismo (España y Francia) para obligar a los habitantes de la badía (desierto) a establecerse en las ciudades para tenerlos bajo control, llevó al poeta a instalarse en la ciudad en busca de un empleo para mantener a su familia. Se emplea en la empresa "Cubiertas y Tejados", en un trabajo muy duro, con un sueldo que él considera irrisorio. Se mantuvo trabajando hasta 1968 cuando decidió volver nuevamente a la badía. En 1972 hubo una gran sequía que se llevó casi todo su ganado. Sólo le quedaron dos dromedarios machos y una hembra. Esto le afectó mucho dado que tenía nueve hijos y pocas eran las fuentes de trabajo para mantener a su familia. Contaba con algunas cabras, que en casos muy raros podía vender para solucionar un imprevisto. En aquel contexto, rodeado por la vida de la ciudad y en la adversidad, compuso este poema, llamado Predicción, en el que recuerda que para cualquier ser humano lo importante debiera ser darse cuenta que "la vida es sólo un paso y que al final todos somos de Dios y a Él volveremos".

Ser humano, eres extraño en la tierra

$y$ habitas en una casa con vanidad,

pides permiso para ausentarte

$y$ pides un pasaporte para tu edad.

Ser humano por qué te arrastras

entre la masa y el adobe, la piedra,

el cemento, el hierro y la cal

$y$ te rodeas de un muro de ladrillos

y lo adornas con lozas en consideración

para encandilar los ojos de los creyentes.

La porcelana que maravilla y las flores

y los tapices de hilo desplegados

para completar la fortaleza

tú que disfrutas de los palacios

y en cualquier momento te citan a un lugar

en los sepulcros que no podrás evitar.

Escogidas tus medidas, el pico 
entre tus manos y tus ramas arrastradas,

y la muerte te visita cada día

al borde de un palmo de excavación.

Y tú adorando a una flauta

$y$ preparas tu ser para pecar

y engordas tu cuerpo para el infierno,

los gusanos y la bruma de las sepulturas.

Juegas presumiendo de bienes y posesiones,

de tesoros ocultos y descubiertos,

los ropajes en cada orientación

y el barco surcando divinos mares,

el auto trabajando y no eres nadie

si no te apoderas del avión.

Esto no te valdrá el día que tengas que partir dejando congregados a tus parientes y amigos, examinado por los que odiaste y lo que te odiaron.

¿Cómo te has de sentir, vanidoso?

Ser humano, eres extraño en la tierra

y habitas en una casa con vanidad,

pides permiso para ausentarte

$y$ pides un pasaporte para tu edad.

¡Oh ser humano, acaso no sabes

de la casa de las tinieblas que te espera!

Donde no estarán ni tus cabras ni camellos

y por ellos serás preguntado en cada paso,

te preguntarán por cuántas monedas gastadas

en la imagen, el despilfarro y la ostensión,

en qué has gastado tus ahorros

$y$ cuáles son tus negocios ;Oh vanidoso!

Cómo es tu ayuno y tus oraciones cuantas son

las que has perdido en los cultos de la bendición.

Cuál es tu Zakat y sobre qué cantidad

¡Oh nómada! Divides tu contribución.

Cuánto tiempo has pasado siguiendo

las olas de los tambores de la perdición

para una diversión que es la prueba

de tu sueño mañanero, dormilón, 
fingiendo ser alguien ocupado

cada día construyes una mansión, sumas más empleados y trabajas $y$ en la tierra mercadeas y en el mar,

no sabes que esto será la nada el día que a los cementerios has de partir, será clasificado y repartido, aquello vendido y lo demás sacrificado, de ello no quedará con qué llenarte la boca y acaso mucho menos no podrás encontrar.

Ser humano, eres extraño en la tierra $y$ habitas en una casa con vanidad, pides permiso para ausentarte $y$ pides un pasaporte para tu edad.

¡Oh ser humano! Agradece todo lo dado por el Dueño del universo, el Inmortal y Salvador porque corresponder al Ser Supremo no es sembrar en un terreno yermo y sin valor.

No te distraigas de tu religión, ten cuidado tu riqueza está en manos del Inmortal y Perdonador.

Nuestro Señor desde que te engendró dosificó tus bienes a lo largo de tu vida y te garantizó que no te olvidaría aunque estés en la angostura de las raudas.

Dio a los ángeles la misión de velar por $t i$ y te otorgó la abundancia y la luz para tu visión.

Te enseñó los senderos a seguir $y$ te aconsejó evitar los odiosos caminos.

Y tú queriendo obtener esto y aquello deseando que el dinero se amontone hasta el día que tus testigos afirmen que tanta riqueza nunca fue de provecho. Adorno para los herederos a la hora de tu muerte, serás como un velero náufrago, saqueado y roto.

Ser humano, eres extraño en la tierra $y$ habitas en una casa con vanidad, 


\section{pides permiso para ausentarte}

$y$ pides un pasaporte para tu edad ${ }^{5}$.

Las referencias al Islam en la definición de la vida humana, del "ser humano" (aquí reforzando la relación entre el saharaui y la humanidad), como registra el poema, se convierte en una alternativa a la identificación de la buena vida y el consumo que acompaña la vida de la ciudad moderna, y sus referencias metropolitanas (en su doble sentido de ciudad y mundo colonial). El poema puede ser leído como un recordatorio de la fragilidad humana y del carácter irrevocable de su destino, pero los elementos que se utilizan, y que se encuentran en el gaf central del poema (Ser humano, eres extraño en la tierra/y habitas en una casa con vanidad, /pides permiso para ausentartel y pides un pasaporte para tu edad) componen también, en contraste con la vida libre del desierto, una fuerte crítica a la vida en la ciudad, donde vivir parece precisar el pedir permiso, en pagar un precio (habitar una casa con vanidad) y donde cada persona es censada y controlada (un pasaporte...). Ello es visto como una situación de alienación producida en definitiva por un sistema colonial que hace a los saharauis, como seres humanos, seres extraños en una tierra, que ya no es suya, aunque les pertenece.

4.

En este artículo queremos explorar, a partir de varias entrevistas realizadas sobre la persona de Basiri, impulsor de un movimiento de reclamación del Sahara para los saharauis sobre los acontecimientos de 1970, para adentrarnos en la comprensión de las ambigüedades de las relaciones coloniales. Utilizamos este momento como un tiempo donde se revelan las contradicciones del orden colonial. Ello nos permitirá repensar el proceso de creación de la conciencia en la sociedad saharaui que llevó al apoyo masivo de dicha sociedad al Polisario en 1973.

Nos inspiramos en nuestro análisis en las aproximaciones de la Escuela de Estudios Subalternos de la India, y en concreto el trabajo de Guha (1982). Para Guha, los movimientos anticoloniales (campesinos) en la India, no pueden ser explicados a partir de la creación de una conciencia individual (moderna), sino a partir de la propia lógica de las relaciones sociales y culturales que ligaban socialmente a los campesinos y contribuían a conformar sus prácticas, también las de la lucha contra el dominio británico. Además, la consideración de la ambivalencia de las relaciones, siguiendo el concepto acuñado por Bhabha (2002), permite revisar los mecanismos mediante los cuales las reclamaciones de la población saharaui en 1970 fueron malentendidas y distorsionadas por las autoridades coloniales y el gobierno de la metrópoli, de manera similar a la que plantea Trouillot (1995) para la revolución haitiana de 1790, una revolución que fue invisibilizada tanto

5. Traducción del poeta saharaui, Mohamed Salem Aldelfatah, Enbu. 
por los políticos y analistas de la época, como en los libros de historia, donde la revolución haitiana "no existió", y si existió, "no debió producirse".

En cambio, nosotros queremos plantear aquí que la "diferencia" entre la sociedad española y la sociedad saharaui, construida mediante las relaciones coloniales, desde 1884 , pero sobre todo después de 1958, fue ampliada por la represión y violencia colonial, que si bien no fue generalizada, operó de manera puntual, mostrando claramente la naturaleza colonial de su lógica. Dicha violencia, padecida y percibida por los saharauis en 1958 y 1970 contribuyó a producir a su vez una contraviolencia (en el sentido de Fanon, 1994) alimentando la creación, consolidación y hegemonía del movimiento armado anticolonial liderado por el Frente Polisario. Las tesis de que el Polisario provocó su propia desgracia al plantear la lucha armada, debe ser puesta en cuestión cuando se considera la lógica de la violencia del régimen colonial español. En los momentos donde se hacía evidente que la coerción sobrepasaba la persuasión (en el sentido de Guha, 1997). 1970 constituyó uno de esos momentos. Los hechos que allí acontecieron deben considerarse como un parteaguas de la historia del Sahara Occidental.

\section{5.}

En este apartado recogemos parte de una entrevista realizada en el campamento de Dajla, en febrero de 2012, a su wali (o gobernador) Salem Lebsir6. Lebsir fue uno de los más íntimos colaboradores de Basiri, y nuestra entrevista versó sobre su figura. Subrayamos las partes de la entrevista que nos servirá para la discusión central en el artículo, que desarrollaremos después.

"España estaba colonizando el Sahara en aquella época, también se produjeron varios encuentros entre países del Magreb, sobre todo Argelia, Marruecos y Mauritania, se reivindica la liberación del Sahara. Según testigos, esos encuentros son para liberar el Sahara, no había ningún interés de esos país por ocuparlo. Más tarde se vio que sí había intereses en medio, sobre todo de Marruecos. Entonces presionan a España en las Naciones Unidas para que libere el Sahara. España aceptó el referéndum, pero no dieron plazo, hicieron un censo para hacer el referéndum en el 74. Vieron la posibilidad de hacer un referéndum con todo el pueblo saharaui, manifestando que el pueblo saharaui quiere ser una provincia más de España, trabajaron sobre este objetivo. El pueblo saharaui todavía era inconsciente, no sabía nada de todo lo que se tramaba. Nadie sabe lo que se trama.

Vino Basiri, porque estudió en Marruecos en los 50, como tantas familias que huyeron por la guerra con España. Sus primeros estudios fueron en Egipto y Siria. Cuando volvió a Marruecos comenzó a escribir en un periódico. En el periódico marroquí escribió que el

6. Esta entrevista fue realizada en español por Juan Carlos Gimeno, Víctor Bober y Jesús González, en la wilaya de Dajla, campamento de refugiados saharauis al sur de Argelia, en febrero de 2012. Agrademos a Víctor Moral la transcripción de la entrevista. 
Sahara era de los saharauis, no puso su nombre, simplemente firmó como "Saharaui". Ese día no le vieron en el periódico y fueron a buscar a Basiri. Él huyó al sur de Marruecos y entró en Smara, las autoridades españolas le cogieron y encarcelaron en principio, vinieron sus familiares y el jefe de tribu y le liberaron, pero siempre bajo vigilancia, bajo control, le dieron un documento provisional. Siempre ha sido una persona sospechosa, sin documentos y bajo vigilancia. Él se dedicó a estudiar, empezó a ver a gente de diferentes edades, hizo un aula para enseñar árabe, también varios encuentros con personas mayores. Los últimos meses se reunió con un juez muy famoso, se reunía con él diariamente, con sus libros, etc. Más tarde, en 1969, la situación política con España hacía difícil el poder salir a manifestarse, estaba prohibido. Tampoco nadie podía formar un partido o hablar de política, sobre todo en el Sahara. Estaban los jefes de tribu, para nosotros que eran personas muy cercanas al gobierno español, entonces todo lo diario siempre va al gobierno. Hay gente reclutada como informadores y oficiales en el ejército, las tropas nómadas. Era muy difícil que tú dijeras una palabra en contra del gobierno español. Una tarde la radio de Londres dijo que los dos periódicos, el Guardian y el Times dieron una información sobre el futuro del Sahara, que lo van a repartir entre los países vecinos. Anteriormente habían dado Sidi-Ifni o Tarfaya... siempre hablaban, pero ahora con definición. Esa tarde nos reunimos un grupo de jóvenes en casa de un amigo. Empezamos a hablar sobre la información de que iban a partir el Sahara entre los países vecinos y nos preguntábamos “¿qué vamos a hacer?”.

Basiri estaba allí. Basiri no habló porque tenía miedo. Al día siguiente concertamos otra cita para hablar sobre el caso, pero no teníamos información ni experiencia, solamente la reacción de que no podíamos soportar esto. Ahora, ¿de qué forma lo hacemos? ¿Cogemos piedras y las tiramos contra el gobierno? ¿Hacemos una manifestación? No sabemos todavía el hilo que vamos a coger. Él tampoco habló, solamente escuchaba. Al tercer día, por la mañana, yo lo encontré y me dijo "bien, de lo que hemos hablado ayer y antes de ayer, no se puede hablar así en un grupo en el que hay tanta gente y no sabes quién es cada uno. Si quieres que hablemos con más detalle, llámame".

Le llamé una noche y nos encontramos para hablar, él dijo "yo he participado dos noches en vuestras reuniones y había gente que no conozco. Aquí puedo hablar porque tengo confianza con ustedes. Podemos hablar de si el futuro es que España va a distribuir el Sahara. Si queréis hacer algo es difícil. Vais a tener que arriesgar vuestra vida, tienes que saber que hay tortura, prisión perpetua o van a acabar con vuestra vida en el momento. En esa trayectoria no va a haber un día bueno." Yo dije que nosotros sólo queremos nuestra libertad, cueste lo que cueste. Él quería compromiso. Tomamos varias experiencias de otros países como Cuba, Argelia, Libia, Mozambique o Sudáfrica, experiencias de pueblos que se liberaron, unos de manera armada, otros con movimientos políticos. Lo más semejante a nuestro movimiento fue la liberación argelina.

A las 3 de la mañana nos pusimos de acuerdo en el nombre que le vamos a poner al movimiento, que es Movimiento por la liberación de Saguia Al-Hamra y Río de Oro. $\underline{\text { Hemos }}$ 
jurado en el Corán, para nosotros es un texto sagrado que tiene su bien y su mal. A las 3 de la mañana terminó nuestra cita, al día siguiente elaboramos una constitución y los cargos que íbamos a ocupar: estaba el secretario general, que era él, un secretario adjunto, y otros cargos para cada uno. Hemos empezado a estudiar de él, qué hacemos, qué línea vamos a seguir. Nosotros éramos muy jóvenes y teníamos que aprender de él. Cada noche hacíamos encuentros. También empezamos a reclutar gente, a través de amigos y familiares nada más, porque el miedo existe y los obstáculos son muchísimos, y no sabes con quién puedes tener confianza. Después ya fuimos ampliando, gentes de oficinas, etc. Él es muy ágil, y en seguida sabe por dónde van los tiros. Se fue al Aaiún a sensibilizar a la gente y a hacer encuentros, en uno de esos encuentros conoció a Jatri Said Yumani, el presidente de la corte española en el Sahara, y habló con él, sus familias eran amigas. Se lo contó todo, le dijo que estaban haciendo un frente para la liberación del Sahara y que querían que él fuese el futuro presidente. Yo también hablé con Jatri, y él estaba de acuerdo. Ya teníamos una piedar en la mano. Jatri no es fácil, pero él logró convencerle.

En aquella época España trabajaba para hacer ese referéndum. Hubo un gran encuentro de los saharauis para manifestarse en frente de una delegación de la ONU. Nosotros trabajamos con dos objetivos: una línea politica pacífica y un ala militar. Buscamos armamentos y municiones. También escribimos una carta a Argelia, que llevó un enviado que es Ahmed Algaib (¿?), que ahora está en El Aaiún, pidiendo ayuda militar e informando sobre la organización. La respuesta fue que nos ayudarían con todos los medios que pudiesen. Preparamos 300 personas para ir a Argelia, a hacer construcciones, hemos trabajado para reclutar a población civil. Teníamos casi todos los municipios del Sahara, entre todos los municipios reclutamos unos 18000, que es muchísima gente. España trabajaba en el referéndum, no un referéndum donde la gente va a votar, sino una manifestación en la que la gente saharaui va a decir "nosotros somos españoles y queremos ser la 53 provincia". Entonces las dos partes aprovecharon, nosotros aprovechamos el transporte que mandó el gobierno español.

Mandaron camiones para todas las provincias, para que la gente vinieran a la manifestación oficial. Nosotros aprovechamos para ir en ese transporte y empezamos a hacer mítines, porque ya entonces el gobierno español sabía la existencia de un movimiento que quería la independencia. En esos días Basiri y el grupo se reunieron y escribieron un documento que se grabó después en un casete. Se mandó un casete a cada oficina donde había un delegado español, un documento que hablaba sobre la historia saharaui y la forma en que entraron los españoles. Había un acuerdo entre saharauis y españoles, en el que los españoles aceptarán y respetarán el momento en el que el pueblo saharaui diga que ya pueden por sí mismos, que quieren su independencia, que el gobierno español se retirará. El segundo punto era que queremos la independencia, si no se nos puede dar en el momento, que en un periodo de 10 o15 años vayan cambiando los gobernadores por saharauis, paulatinamente. Que vayan entregando poco a poco el Sahara. Ese día, el 17, los españoles no tocaron nada, trabajaron 
para comprender qué es esto. Sacaban un informe diariamente.

El día anterior decidimos montar jaimas en Zemla, para diferenciar de las casas de piedra, donde se iba a hacer el mitin oficial. Trajeron gente del sur y de Dajla, intentamos convencer a toda la gente del sur que iban a ir a las casas de piedra con el resto de la gente. Hicimos una comisión para dialogar con el gobierno español. Mandaron un comandante, pero no hubo entendimiento. Vino otro, el gobernador militar, y dijo "nos comprometemos a contestar, pero requiere tiempo que el general lo firme". Nosotros queríamos algo escrito, no de palabra. No hubo forma, la negociación fue hasta las 5 de la tarde, lo intentaron todo para convencer a la gente: trajeron a jefes de tribu, a familiares, personas de edades diferentes... a las cinco trajeron a los jefes de tribu, los ancianos. Nada más bajarse del coche, la población empezó a tirarles piedras y se fueron corriendo. Después vino la policía, con coches y sus armas, la población fue hacia la policía y chocaron con ellos, hubo heridos, un muerto, y se escapó también la policía. Vieron que esto requiere otro sistema y mandaron a las 7 de la tarde al ejército. Comenzaron a atacar, hubo tiroteos, heridos y muertos. Entonces empezaron a coger a la gente, cogieron a Basiri a las 3 de la mañana, a todos los sospechosos y fichados, porque durante días habían recogido el nombre de todo el mundo. No se pudo firmar el acuerdo, no se pudo hacer un referéndum. Más tarde, a mediados de 72, se liberaron a los encarcelados. Empezaron otra vez a juntarse, había que continuar. Fueron a Mauritania y empezó la revolución del Frente Polisario en el 73. Los encuentros y la preparación se hicieron a finales del 72. El 20 de Mayo se produce la primera operación de la policía, la primera bala."

6.

Entre los detenidos en los actos de Zemla en junio de 1970 estaba Sidi Brahim Salama, actualmente uno de los poetas nacionales saharauis. En la declaración que siguió al interrogatorio de Basiri, Sidi Brahim Salama aparecía, junto a su hermano, como uno de las personas vinculadas a su organización (Bárbulo, 2002). En una entrevista, muy amplia, que realizamos a Sidi Brahim en octubre de 2011, sobre la tumba del guerrero Wayaha $^{7}$, saharaui-mauritano, muerto en Dejen, cerca de Aguenit en combate contra las tropas francesas en 1925, Sidi Brahim nos trasladó su propio recuerdo en torno a los acontecimientos y la figura de Basiri. Tomaremos sus palabras para apuntalar las reflexiones provocadas por la entrevista anterior a Salem Lebsir.

Sus relatos permiten explorar los límites de las relaciones coloniales, límites que tuvieron otro momento histórico muy significativo en 1958, en la operación conjunta franco-

7. Hemos expuesto, siguiendo la metodología de Guha, el contraste entre la historia de Wayaha, recogida en los archivos coloniales y trasladado a la historia de la región, bajo la denominación de bandidaje de frontera, de las representaciones hechas por los combatientes e intelectuales saharauis en Gimeno y Robles, 2013. 
española, Ecouvillon, mediante la cual se fortaleció definitivamente el control colonial de las fronteras.

Sidi Brahim a instancias nuestras ${ }^{8}$ comenzó a relatarnos su relación de lo que consideró un cambio en su vida, y en la vida del Sahara: "En 1958, el año que nombramos el "año del ataque", todos los camellos se murieron por las bombas de los aviones que tiraron sobre un sitio que se llama "el Kreib incraf". Bueno está entre "el kreib incraf" y "el kreib itishia". A día de hoy encuentran ahí los huesos de los camellos, hay hasta 20 camellos. Usaron un truco horrible: hacían un ruido previo al bombardeo para que los animales se reunieran en coros y, cuando lo hacían, soltaban sus bombas... bombardeaban cualquier sitio en el que sospechaban que se podía encontrar el ejército saharaui."

La experiencia de 1958 ha quedado en la memoria de la población saharaui como un hecho donde la violencia colonial se hizo presente. No sólo se habla del bombardeo, sino también de la inutilización de los pastos, de manera que la reproducción de la vida en la badia, se hizo imposible, y muchos saharauis se vieron forzados a moverse hacia las ciudades. Para favorecer ese desplazamiento y contribuir a hacerlo irreversible, las autoridades españolas desplegaron todo un abanico de ayudas, en una política, imaginativa pero útil, que unía "el palo y la zanahoria". Dicha política que ha sido analizada por el historiador Francesco Correale (2012). Muchas historias de vida de los saharauis de cierta edad contemplan la fecha de 1958 como un momento de corte entre su vida en el desierto y el desplazamiento a las ciudades. Sin embargo, lejos de ser un proceso unidireccional, en los siguientes años se dieron retornos al desierto de muchas familias, o de parte de sus miembros, como en el caso de la familia del poeta Alal, que mencionamos antes. Este en un proceso que desconocemos ampliamente, pero que sirve para poner en cuestión el carácter plenamente urbano de la sociedad saharaui en 1975, como muchos analistas han sugerido. Ciertamente la planificación de las ciudades del litoral del Sahara Occidental crecieron sustantivamente en el periodo posterior a 1958 (Rodríguez Esteban y Barreda, 2013), pero la urbanización no acabó con las dinámicas rurales de la sociedad saharaui, ni con un imaginario de los saharauis como población beduina, si bien como mencionamos antes los debates sobre la tensión entre la ciudad y el mundo rural fueron centrales en aquella época (Mahmud Awah, 2013; Gimeno, 2007; Gimeno y Ali, 2007; Robles, Gimeno, Mahmud Awah, y Ali Laman, 2013).

Sidi Brahim Salama que contaba entonces 23 ó 24 años se marchó a la ciudad a buscar un nuevo medio de vida:

"Cuando todos nuestros camellos se murieron, me uní a la escuela militar de Smara en 1960, yo tenía el número 8064. Trabajé bajo el mando de Fernando Regueros Cotila, me

8. Entrevista realizada por Bahia Mahmud Awad, Juan Ignacio Robles, Mohamed Ali Laman y Juan Carlos Gimeno, en Dejen, cerca de la localidad de Agüenit, en los territorios liberados del Sahara Occidental, en octubre de 2011. 
parece que aún sigue vivo. Es de Santander. Allí aprendí un poco de español, él me cogió de traductor. Era el "Coordinador de Harka", en una compañía española, así lo llamaban en aquellos tiempos... su misión era controlar la línea de la frontera desde el Este "Sbeg Greibil" hasta "Weinsrimgan". Yo trabajaba de intérprete y, poco a poco, fui mejorando mi nivel hasta que empecé a trabajar en una oficina de la administración española. Hasta el año 1970 que empezó el movimiento de liberación de Zemla. Había hecho 10 años de servicio."

...Después de coger el permiso, dejé el servicio y fui a reunirme con mi familia en Bir Nzaran en un Land Rover que acababa de comprar. Su matrícula era el número: 3259. Pasé cuatro meses en Tinwaka, en Bir Nzaran. Entre Wara y en Lask y, en el quinto mes, entramos en la ciudad de el Aaiún... Un día vino a la casa Budda wul Ahmed Hamad, un médico que en ese momento trabajaba con nosotros en el dispensario. Era amigo mío y me pidió que le acompañara porque estábamos invitados en una casa, él decía eso para disimular lo que verdaderamente quería decir. Le acompañé, me dijo que íbamos a ver a una gente en Zemla. Cuando ya nos estábamos acercando a la casa de Moussa wul Debsir, me explicó que en realidad no era una invitación sino una cita con una persona que se llama Basiri y que buscaba a personas como a mí. Buscaba a gente que trabajara en la administración española, y que le pudiera pasar informaciones acerca del gobierno colonizador. Me pidió que confiara en él y que me adhiriera a su movimiento. Le pregunté si él formaba parte de ese movimiento y me dijo que sí. Me dijo que no sólo era sólo él, eran muchos quienes ya formaban parte. Toda esta conversación la tuvimos ante la puerta de la casa. Yo le dije que me sentiré bienvenido. Entonces mi compañero se dirigió a Bassiri y le dijo, "la persona de la que te hablaba está conmigo ahora”. Basiri nos invitó a pasar. Entramos y encontré una persona con una barba bien afeitada, tenía una cara muy serena e iluminada... tenía un cigarro en la mano, él fumaba mucho. Se levantó cuando entramos y me pidió que me sentara a su lado. Me dijo: "tú eres fulano" y me dijo mis nombres y mis apellidos y en ti tenemos mucha confianza, dijo, al igual que en otros como usted. "Buda" (mi amigo) es quien nos habló de ti, me dijo. Me hizo un breve resumen sobre el movimiento y me presentó a Shadad wul el Gayed Saleh y Mohamed Mahayub wul Mohamed Abdelrahman Edjil...”. Lo que quisiéramos rescatar de esta parte del relato, así como el anterior de Salem Lesbir, es la consideración de la confianza entre personas conocidas que es previa al hecho de reclutar a alguien para el movimiento. Para cualquiera que conozca el Sahara esa confianza se refiere a la relación derivada entre parientes, una relación que se basa no en los contratos escritos, sino en la palabra dada. En lo que podemos denominar la ideología beduina, la palabra dada de una persona a otro, y más concretamente la palabra dada de un hombre a otro, se consideraba que obliga más que un contrato. Además la confianza se da entre personas que se conocen, y más particularmente en la sociedad sahariana beduina el conocimiento de alguien está fuertemente relacionado con el parentesco compartido, aunque no sólo, pero si principalmente. De ahí la importancia 
del saludo que se extiende como una forma de repasar la vida de las personas conocidas y también para identificar alguna persona que permita la intersección de las dos redes de relaciones de las personas que se encuentran. La confianza es pues, no algo que remite a una dimensión individual de la vida, sino a su dimensión colectiva.

La palabra dada encuentra un reforzamiento a través del juramento: "Antes de todo, juramos sobre el Corán. Juré que nunca engañaría a la patria ni al movimiento ni violaría sus principios".

"Después del juramento sobre el Corán, me explicaron porqué se había formado ese movimiento. Me dijeron que debido a la independencia y las revoluciones de los países de alrededor, nosotros también debíamos movilizarnos con el fin de lograr nuestra independencia. Le íbamos a pedir la independencia a España, al igual que todos nuestros vecinos lo habian hecho, querían negociarla con ella poco a poco. "Vamos a plantear la independencia a España" decían "y observaremos cómo reaccionan". Les plantearemos nuestra politica de igualdad entre los colonialistas y el pueblo, también la igualdad a la que aspirábamos entre el mismo pueblo. La igualdad y la justicia social entre el sector militar y el sector civil". Esos fueron los motivos que me dieron tras la fundación del movimiento". Nos gustaría destacar, enfatizar, la lógica de la sucesión de significados que está contenida en esta situación. La confianza no lleva a pedir información sobre aquello para lo que uno está citado; este hecho sólo se produce después de jurar sobre el Corán. Sólo después se explica por qué se ha formado el movimiento. Este punto nos parece central en la comprensión de la construcción de la conciencia y en la naturaleza de la misma. La concienciación es parte de un proceso colectivo, más que individual. Uno acepta participar en el movimiento en base a la confianza que se tiene en la persona que sirve como intermediación. La información que viene después, en este caso la crítica al orden colonial y las propuestas para la acción, se añade sobre la conciencia de pertenecer a un colectivo social preexistente. No se trata de una conciencia individual como sujeto moderno, sino la aceptación de una lucha colectiva frente a un nuevo antagonista común. Este proceso replica a los gazzyan ${ }^{9}$ de tiempos anteriores.

Esta argumentación que hacemos sobre la acción colectiva en el Sahara es similar a la que plantea Guha (1982) en los movimientos campesinos indios, que para él no estaban animados por la propagación de una conciencia individual que permitía a una pluralidad de individuos concienciados una acción común, normalmente detrás de las élites que formaban la vanguardia donde esta conciencia estaba más elaborada. Guha aquí discute la pretendida naturaleza pre-política de los movimientos campesinos, tal como propuso Hobsbawn $(1959,1969)$, en sus libros sobre el bandidaje social. La pretensión pre-política de los campesinos tiene como consecuencia su consideración como no-contemporáneos de aquello a lo que se enfrentan, aunque coexistan en el mismo tiempo.

9. Plural de gazhi (razzia). 
"El mismo día en el que hice un juramento ante Basiri y los otros miembros y gracias a mi amigo "Budde", Basiri me escribió una carta y me pidió que la llevara al "bureau legislativo del movimiento en Smara". Se la tenía que entregar a Abdala wul Jai y a Salama wul el Mamen, y a Salem Wul Lebasir y Sidi wul Lebasir. ...Yo no leí la carta, pero él me había dicho que cuando llegara a la casa, debía tocar la puerta nada más que tres veces. Si tocaba más de tres veces sospecharían de mí...".

"Los españoles tenían información... el teniente Coti Garrido (sic) tenía información de que se estaba creando un movimiento y nos pedían a todos que acudiéramos. Hay alguien que les había filtrado algunos de nuestros nombres. Unieron a todos los gobernantes, a todos los que estaban al mando del ejército y trabajando para el gobierno español. Había uno que se llamaba Mohamed Wul Gaha que es quien nos había traicionado. El Frente POLISARIO conoce el nombre de esa persona aunque nunca quisieron nombrarlo".

Aquí se encuentra la otra cara de la moneda, la otra cara de la confianza es la desconfianza. El orden colonial había multiplicado la densidad de las relaciones entre los funcionarios coloniales y los saharauis contratados en empresas, en las tropas nómadas. Los notables de las tribus habían sido reconocidos por el régimen colonial que había buscado su intermediación como brokers sociales y políticos, introduciendo un principio de ruptura en las relaciones de los saharauis entre sí. En las entrevistas realizadas en nuestro proyecto con los poetas saharauis contemporáneos, muchos de ellos señalan la importancia de la poesía y las canciones para desenmascarar a los chivatos, como refleja este fragmento de un poema de Hussein Mouloud; lo peor de un chivato era que se trataba de "uno de los nuestros":

Si alguien encuentra a los chivatos/quemadlos en el fuego./Esto es lo que dice la sharia sobre ellos./El chivato husmea dentro de las jaimas, /busca algo sobre lo que dice la gente./ Se reconoce el falso pensamiento vendiendo a sus hermanos,/a los gobernantes, vende a sus familiares.

Por otra parte, la confianza era también el lenguaje que se había impuesto en las relaciones entre saharauis y funcionarios de la metrópoli, sobre todo en algunos ámbitos donde la actividad o el trabajo llevaban a compartir un lugar sobre la tierra. Esto se daba especialmente en el desierto, donde las patrullas de los grupos nómadas estaban compuestas por pocos españoles y un número grande de miembros saharauis. En el desierto, los militares españoles dependían de los saharauis, mejores conocedores del hábitat. La relación de una relativa camaradería estaba extendida, especialmente en estos espacios, y era favorecida por una historia de relaciones coloniales donde la debilidad española como potencia colonial hizo desarrollar estrategias centradas en relaciones paternalistas que suavizaban sus formas y que muchos saharauis presentan como una relación de hermanamiento: "allí vivíamos como si fuéramos una sola familia, los españoles y los saharauis. Ningún español ha tenido queja de ningún saharaui, ni ningún saharaui de ningún español. Hemos vivido y convivido como una sola familia."..."Ya eso 
lo he dicho veinte mil veces diciendo de que cuando los españoles que estaban en el Aaiún, en Villa Cisneros, en la Güera, en Smara... y los saharauis, éramos una sola familia, una sola familia. Nos entendemos, nos ayudamos, en todo. ¿Comprendes?", (notable, B, A, entrevistado en diciembre 2009).

Estas formas cotidianas de convivencia interpersonal están también recogidas en el recuerdo de Sidi Brahim Salama sobre los acontecimientos que desembocaron en la manifestación de Zemla de 1970. El gobierno español tenía noticia de que algo se estaba organizando y un teniente que le tenía confianza se acercó a Sidi Brahim Salama donde fue preguntado por un oficial español: "Pasó a por mí el teniente Garrido y me dijo que nos íbamos a reunir con otro teniente en Yideria que se llamaba Jorge. Le acompañé hasta un sitio que se llama "Gat Mesual". Aparcamos ahí el coche, bajó del coche cogiéndome de la mano y sosteniendo en la otra un sobre. Nos alejamos del coche. Sacó una lista, la doble y mostró sólo mi nombre, dijo: "este es tu nombre y apellido?" "Sí, dije". Me dijo: "Tu y los demás estáis metidos en una organización de un movimiento al mando de Basiri". Él me tenía mucha confianza. Le dije que no es algo grave, era simplemente un movimiento que iba a pedirle unos derechos a España. Es un movimiento de paz, nada más. A él le gustó, reaccionó bien a lo que le contaba y cuando llegamos a Yidería se lo contó al teniente Jorge. Cuando volvimos a Hausa me pidió que le acompañara al General que está en El Aaiún y que le hiciera el favor de hacerle un contacto con Basiri o con alguien cercano a él para negociar con él esas peticiones, decía que las veía razonables. Decía que es algo negociable, que eran pedidos sociales y se pueden hablar pacíficamente. Llegamos a la residencia oficial en El Aaiun y me despedí de él allí diciendo que me iba a conectar con Basiri, y me fui".

Me puse en contacto con Basiri, le conté lo que había pasado. Me dijo que bien, que no había ningún problema que nos podía visitar y hablábamos. Le dije que me diera el sitio donde se podía encontrar con ellos y me citó en la casa de "Mint Habiba" en un lugar que se llamaba "la Colomina vieja" a las 9 de la noche si dios quiere. Me contacté con él y le di la hora y el sitio. Me dijo que acudiera a él en mi propio coche porque no quería ir con su coche oficial para pasar desapercibido. Bueno, le recogí con mi coche, nos fuimos a la casa donde habiamos quedado y, al llegar, nos encontramos a los hombres esperándonos pero tenían todos las caras tapadas con turbantes. Shadad Kaid Saleh wul el Mahyub y Basiri, Buda wul Ahmed. Saludamos al grupo, eran más que esos, nos saludaron. Le explicaron su movimiento y sus peticiones. Les contó Garrido lo que tenía. Apuntó lo que le habían pedido y le dijo: "Si no estaré con vosotros, no estaré en contra. Confiad en mí. Lo que estáis formando es algo bonito y ya os vendré con la respuesta". Cogió las peticiones y me dijo que volvería a por mí pasado mañana. Cuando volvimos a encontrarnos me dijo: "Hijo mío, la respuesta del Gobernador es muy negra... Lo siento. Lo siento.. Ga" Aquí, Sidi Brahim Salama hace alusión a las lágrimas que aparecieron en el rostro del militar español y a sus palabras entrecortadas como si estuviera totalmente convencido de su pena por la situación creada. "Vamos a decírselo a tus compañero, pero lo siento mucho. La respuesta 


\section{del gobernador es muy negativa, está en contra de todo esto".}

Sidi Brahim regresa con sus compañeros para comunicarles la noticia: "Les conté que el General (gobernador) había dicho que pedíamos demasiadas cosas, que las peticiones eran demasiado grandes y que él no tenía el poder de solucionarlas o tomar decisiones sobre ellas sin que se comunicara y se decidiera en Madrid. Que tenían que coordinarlo con el estado de España". Basiri reaccionó a la noticia, diciendo que los saharauis debieran platear su propia agenda y presentarla, si los colonos iban a organizar sus reuniones por el territorio tratando de mostrar al mundo el apoyo de la población saharaui al gobierno español, los saharauis se organizarían para mostrar su propia agenda....Todo ello desembocó en la tragedia del 17 de junio de 1970, donde varios saharauis murieron, otros fueron detenidos; Basiri fue detenido y desapareció sin que se sepa aún de manera oficial cuál fue su destino, y dónde se agotó la vía de la negociación pacífica hacia la descolonización del territorio.

"Yo estuve ahí, vi todo lo que ocurrió" relata Sidi Brahim Salama ${ }^{10}$ :

"Los heridos, algunos los llevaron al hospital y otros se fueron a Gdeim Izik. Los que se fueron a Gdeim Izik, la mayoría los trataron con medicina tradicional hasta que se curaron. Yo pasé dos noches en la casa de Ehel Zeiou y vinieron por la noche llamando a las puertas de las casas y buscando a la gente que participó en las reuniones. Hicieron una gran redada de la que capturaron a 200 personas. Yo me salvé de la cárcel y regresé a Hausa donde me encontré con un Sargento amigo mío. Cuando llegué, quité las ruedas del coche y las metí en el cuartel de policía. Mi amigo me dijo que dejara con él el coche. Después de una semana de trabajo cotidiano. Después de un tiempo trabajando con él como traductor me envió uno de los policías que se llama Brahim wul Mohamed Lemin wul Mustafa, un musulmán. Uno

10. El relato del acontecimiento de Zemla que conocemos está sensiblemente sesgado por la fuente de información desde el que se produjo, tanto los documentos oficiales como por las crónicas periodísticas de aquellos días. La tesis de Pablo Ignacio Dalmases (2013): El Sahara Occidental en la bibliografía española y el discurso colonial abunda sobre este punto. Dalmases $(2013,559)$, recoge otras fuentes, esta vez saharauis. El mismo co-director de su tesis, el filólogo saharui y profesor de la Universidad de Granada, Larosi Haidar, le aporta un testimonio de alguien cercano a los acontecimientos: "El capitán...se acercó gritando a los manifestantes y se encaró a uno de ellos. Antes de que pudiera reaccionar, el manifestante le dio un tortazo. El capitán reaccionó disparándole a boca jarro con su pistola en el vientre. Es el primer disparo y a parti de ahí, el descontrol. La mujer le quita la pistola con una especie de bate con el que estaban removiendo la comida en enormes cacerolas. La mujer es Ibzaha, mujer del conocido Diablo Biruk de Tantan, que estaba de visita; fue devuelta a Tantan con prohibición de regresar. El hombre que abofeteó al capitán sobrevivió, pero estuvo aquejado de la herida hasta que murió en Aaiún en los años ochenta. Fue Mohamed Salem Hiadar, mi tío, primo hermano de mi madre". Este relato lo compartió también Larosi Haidar con los autores de este artículo en un seminario realizado en la Universidad Autónoma de Madrid, el día 17 de junio de 2013. 
que ahora es Secretario General de uno de los Ministerios, le llaman "Titi”. Me pidió Jaime Coti que volviera para trabajar con él. Me acompañó. Llevaba su arma y me acompañó. Creo que le habían pedido que me aprisionara pero él me trato de otra forma, anduvo a mi lado.

Cuando llegué con el policía. Me dijo Jaime: "lo siento muchísimo, pero la policía te busca". Te van a acompañar dos agentes míos. No te tratarán mal, pero no hables con ellos. Ellos te llevaran hasta Smara. Me acompañaron dos delante y dos detrás. Cuando llegamos a Smara me metieron y me encarcelaron. Me acompañó Sidi wul lebsir, pasamos una semana, después vino un informe que decía que me tenían que llevar al cuartel de policía de El Aaiún. Entré ahí en una barraca y vino a investigarme el teniente alcalde. Me dijo que tenía confianza en mí y que quería que le contara toda la historia, cómo sucedió. Le conté toda la historia de cómo me uní al movimiento, apuntó todo en su libreta y me trasladaron a la cárcel central que es lo que se conoce hoy como la Cárcel Negra del Aaiún. No me tocaron ni me hicieron nada. Me trataron bien. Contrastaron la información que ya tenían y coincidía con lo que yo les había contado. Compararon las fechas, estaba todo en orden".

Hay una serie de cuestiones en las que insistió Sidi Brahim Salama que se repitieron en el interrogatorio, que en su caso no conllevó ningún tipo de violencia física. No le tocaron. Una y otra vez le preguntaban quien realmente estaba detrás de aquella operación. A los funcionarios del gobierno español les parecía imposible que un acontecimiento como aquel hubiese sido planificado y llevado a cabo por los saharauis. Aquí debemos plantear dos cuestiones. La primera debido al propio paternalismo del régimen, los españoles fueron víctimas de su propia construcción ideológica acerca de la bondad del régimen colonial.

La segunda cuestión que nos surge es más profunda y tiene que ver con la naturaleza ideológica del colonialismo que sencillamente vuelve impensables ciertas transformaciones. Bourdieu (1991) define lo impensable como aquello para lo que se carece de instrumentos capaces de conceptualizarlo. "En lo impensable de una época está todo lo que uno no puede pensar por falta de inclinación ética o política que predisponga a tenerlo en cuenta o en consideración, pero también que no puede pensar por falta de instrumentos mentales, a saber, problemáticas, conceptos, métodos y técnicas". En este sentido, el levantamiento de Zemla, a pesar de los informes que tenía el gobierno colonial español ( $y$ a los que se refiere Sidi Brahim Salama) era impensable en su tiempo: desafió el marco conceptual en el que los colonizadores habían pensado a los saharauis, el colonialismo y las relaciones coloniales en el Sahara.

Todo el sistema de dominación se basaba en la normalidad. El reconocimiento de la resistencia como un fenómeno generalizado habría reconocido que algo iba mal en el sistema, y esto estaba alejado de la concepción del sistema colonial español en el Sahara, en sus intenciones, en su ejecución y en su resultado. Las intenciones buenas de un régimen paternalista cuyo único objetivo se decía era beneficiar a los mismos saharauis, 
al punto de convertir el territorio del Sahara español en provincia española. Por otro lado, la práctica del ejercicio colonial cuidadosa y atenta con el equilibrio y la toma en consideración de las prácticas culturales de la sociedad saharaui (Sánchez, A. y Campos, A., 2013) incluyendo la religiosidad del islam, así como la articulación como gobierno indirecto a partir de los notables de las cabilas saharauis (Correale, 2012).

A esto se añadía el conocimiento que el régimen colonial creía tener sobre la sociedad saharaui, alimentado por su relación directa con los chiuj (notables) y con los intermediarios, así como los confidentes (o chivatos). Cualquiera que conociese a los saharauis, y tuviese información en 1970 tanto de las ciudades como de la vida del interior gracias a la ocupación efectiva de los puestos de interior y fronterizos, tenía que darse cuenta de que era simplemente imposible reunir a la gente para actuar unidos (como hicieron en Zemla el 17 de junio de 1970). Los saharauis no podían concebir tamaña rebelión por su cuenta (de ahí la insistencia en los interrogatorios tratando de buscar quien había detrás de la revuelta, en la seguridad que el levantamiento debía ser la consecuencia de conspiración de agitadores extranjeros). Es posible que esta ceguera tenga algo que ver con la terrible desaparición de Basiri presionado hasta el límite en los interrogatorios para que dijera algo que era imposible que pudiera revelar, puesto que en el mismo acababa el camino que permitía explicar la manifestación de Zemla y la petición al gobierno español.

La actuación represora del 17 de junio de 1970 se basaba en algo que para muchos era evidente. Una acción como esa sólo podía ser temporal, todo regresaría al orden establecido. Y ese orden que reflejaba la normalidad era el resultado de una asunción: la hegemonía española es natural y se da por sentada; y cualquier alternativa a ella es impensable.

La aparición del Frente Polisario tres años más tarde (en 1973), no cambió el planteamiento del gobierno español, incapaz de considerar la mayoría de edad de la población saharaui, su consideración como sujeto político. La sociedad saharaui no podía convertirse en protagonista de su propia historia. Ciertamente había un pueblo saharaui, pero sólo desde el punto de vista cultural, no desde el punto de vista político. El Sahara seguía, a su juicio, necesitando la tutela colonial durante algún tiempo; si algo pondría esto en cuestión no sería algo que proviniera de adentro sino de afuera, de los países vecinos. Marruecos, tras la ocupación del territorio, ha funcionado con la misma lógica colonial, desconsiderando al pueblo saharaui.

Hasta ahora hemos planteado que la cadena de acontecimientos que constituyeron el levantamiento de Zemla y el posterior surgimiento del Frente Polisario eran inimaginables antes de que estos ocurrieran ( $\mathrm{y}$ ello a pesar de toda la historia regional reciente de descolonización de sus vecinos, Marruecos, Mauritania, Argelia, y los demás países africanos).

No tenemos espacio aquí para desarrollar debidamente el siguiente argumento, pero 
queremos dejarlo apuntado. El Sahara y sus poblaciones han sido introducidos en la historia y los libros de historia, como una sociedad beduina (es decir pastoril) que ocupa una posición muy atrasada en la escala evolutiva (por detrás en el tiempo de las sociedades urbanas y de las sociedades rurales). Sus formas de vida se corresponden en consecuencia con prácticas no sólo no contemporáneas, sino obsoletas, de ahí la justificación colonial de su asentamiento en las ciudades como condición de su acceso a la condición moderna. Esto ha conllevado banalizar su existencia y reducirla a formas de subsistencia obsoletas (e irracionales) así como a menospreciar sus formas de lucha, considerándolas mera disidencia o bandidaje y no como forma de lucha anticolonial. El resultado ha sido una banalización de su historia. Dicha banalización se ha extendido a su territorio y a su situación contemporánea. Cualquiera puede leer que el Sahara Occidental era uno de los territorios con más recursos de África, y la región con mayor renta per cápita del continente para 1974; ahora es presentada como una región sin importancia en la explotación de recursos y por lo tanto en la geopolítica mundial. Frente a ello la RASD quiere poner continuamente encima de la mesa la cuestión de los recursos del Sahara, y su expolio por parte de Marruecos con la connivencia de la comunidad internacional. La estrategia de banalización se acompaña de una campaña de silenciamiento. El Sahara Occidental está fuera de las prioridades de la información mundial, pero también de la agenda de investigación científica y de su consideración en las políticas de estado de Francia y España. En el primer país se trata de un asunto que está incluido dentro de los secretos de Estado, en el segundo, dentro del ocultamiento sistemático. La estrategia de silenciamiento tiene como resultado borrar la historia. De hecho Marruecos practica hoy con mucha dedicación esta política para eliminar los rastros de la colonización española del Sahara, para imponer así su propia versión colonial de la historia (de nuevo negando la condición de sujetos a los saharauis).

Una historia colonial, una historia que sirve directamente al poder colonial, pero también una historia que coloniza los sujetos sobre los que habla y opera siguiendo una ilusión: lo que sucedió es lo que debiera haber sucedido según los intereses de quienes escriben la historia.

Es un desafío construir otra historia que permita distinguir lo que pasó, de lo que se dice que pasó. Esa historia no sólo deberá recoger testimonios como los que hemos traído hasta aquí, que desmienten otras interpretaciones y las subvierten, sino también ser producida por aquellos que son historiados, silenciados, banalizados, reclamando el derecho a narrar su propia historia ${ }^{11}$.

11. La construcción de una contrahistoria del Sahara, siguiendo la inspiración de Foucault, es una tarea que empezamos a realizar en Gimeno y Robles, 2013. 


\section{REFERENCIAS BIBLIOGRÁFICAS}

Bárbulo, Tomas (2002) La historia perdida del Sáhara Español. Barcelona: Destino.

Bourdieu, Pierre (1991) El sentido práctico. Madrid: Taurus.

Bhabha, Homi (2002) El lugar de la cultura. Buenos Aires: Manantial.

Correale, Francesco (2012) "Levantar los camellos para aplastar el espacio: la invención de las ayudas sociales (1959-1975)”. CIEA8, Madrid.

Correale, Francesco (2013, en prensa): "La narration de l'histoire en situation de crise. Revendications et contradictions dans la construction mémorielle sahraouie”. Cahiers d'Emam.

Dalmases, Pablo Ignacio (2013) El Sahara Occidental en la bibliografía española y el discurso colonial. Tesis presentada en la Universidad Autónoma de Barcelona.

Fabian, Johannes (2002) Time and the Other: How Anthropology Makes Its Object. Columbia: University Press.

Fanon, Franz (1994) Los condenados de la tierra. México DF: Fondo de Cultura Económica. Foucault, Michel (1976) Genealogía del racismo. Madrid: Caronte.

Gimeno, Juan Carlos (2007) Transformaciones socioculturales de un proyecto revolucionario: la lucha del pueblo Saharaui por la liberación. Caracas: Programa Cultura, Comunicación y Transformaciones Sociales, CIPOST, FaCES, Universidad Central de Venezuela. http://www.globalcult.org.ve/monografias.htm [Consultado el 10 de agosto de 2013]

Gimeno, Juan Carlos y Alí, Mohamed (2007) “Transformaciones socioculturales en los campamentos de refugiados saharauis del sur de Argelia (1975-2005)”. En J.C. Gimeno; O, Mancha, O. y A. Toledo (eds.) Conocimiento, desarrollo y transformaciones sociales. Madrid, SEPHA.

Gimeno, Juan Carlos y Pozuelo, L. (2010) "Memorias orales en el Sáhara Occidental: la poesía en hasanía”. Lisboa: CIEA7.

Gimeno, Juan Carlos y Robles, Juan Ignacio (2013, en prensa) "Vers une contre-histoire du Sahara Occidental” en Cahiers d'Emam.

Guha, Ranajit (1982): “On some Aspects of the Historiography of Colonial India”, en Ranajit Guha, (ed.) Subaltern Studies I. Writings on South Asian History and Society. Oxford, India: Paperbacks.

Guha, Ranajit (1997) Dominance without Hegemony. History and Power in Colonial India. Cambridge: Harvard University Press.

Hobsbawm, Eric (1959) Rebeldes Primitivos, Barcelona, Ariel.

Hobsbawm, Eric (2000) Bandidos. Barcelona: Crítica.

Leyva, X., Burguete, A. y Speed, S. (2003) Gobernar la diversidad: experiencias de construcción de ciudadanía multicultural. Una investigación colaborativa. México D.F.: CIESAS, Fundación Ford y Universidad de Austin, Texas. 
Mahmud Awah, Bahia (2011) La maestra que me enseñó en una tabla de madera. Malaga: Editorial Sepha.

Mahmud Awah, Bahia. (2013, en prensa) "Générations littéraires: intellecutalité et politique dans le Sahara Occidental, 1850-1975”. En Cahiers d'Emam

Robles, J.I.; Sáez de Buruaga, A.; Mahmud Awah, B.; Aziza Brahim y Zahra Hanaui (2012) "Patrimonio cultural saharaui". En P., Martínez Lillo; J. C. Gimeno; Arias, S. y Tanarro, C. (eds.) Memoria y tiempo presente del Sáhara Occidental. Política, cooperación y cultura. Madrid: Universidad Autonoma de Madrid.

Robles, J. I.; Mahmud Awad, B.; Gimeno, J.C. y Ali Laman, M. (2013, en prensa) "La poésie sahraouie et le début de la conscience nationale" en Cahiers d'Emam.

Rodríguez Esteban, José Antonio (ed.) (2011) España en África. La ciencia española en el Sáhara Occidental, 1884-1976. Calamar Ediciones.

Rodríguez Esteban, José Antonio y Barredo, D. (2013) “Le processus d'urbanisation dans le Sahara espagnol (1884-1975): une composante essentielle du projet colonial”. Cahiers d'Emam.

Sánchez Diez, Angels y Campos Serrano, Alicia (2013, en prensa) "Ressources naturelles et seconde occupation coloniale du Sahara Espagnol, 1959-1975." En Cahiers d'Emam. Trouillot, Michel-Rolph (1995) Silencing the Past. Power and Production of History. Boston: Beacon Press. 